\title{
Heart Failure Related to Large Hiatus Hernia: a Case Report
}

\author{
Ali EROL ${ }^{1}$, Nizameddin KOCA ${ }^{1}$, Fatma Özlem ARICAN ÖZLÜK ${ }^{2}$
}

${ }^{1}$ Health Sciences University, Bursa Yüksek İhtisas Training and Research Hospital, Department of Internal Medicine, Bursa, Turkey

${ }^{2}$ Health Sciences University, Bursa Yüksek İhtisas Training and Research Hospital, Department of Cardiology, Bursa, Turkey

\begin{abstract}
Heart failure is a disease that may present with various presentations depending on different etiological factors. External pressure on the heart is one of the rare causes that can cause heart failure. Here, we presented a 73-year-old female patient with inoperable endometrial cancer who developed heart failure due to hiatal hernia compression.
\end{abstract}

Turk J Int Med 2021;3(Supplement 1):S49-S51

DOI: $\underline{10.46310 / \text { tjim. } 873597}$

Keywords: Hiatus hernia, heart failure, hypotension

\section{Introduction}

Hypotension is defined as a blood pressure less than $90 / 60 \mathrm{mmHg}$. Its etiology includes anaphylaxis, cardiac tamponade, right heart failure, hemorrhage, dehydration, shock, adrenal insufficiency, life-threatening arrhythmias, tension pneumothorax, and pulmonary embolism. Mass, lymph node, or hiatal hernia, which can cause heart failure by external pressure on the heart, are less common causes. Hiatal hernia is the herniation of organs in the abdominal cavity to the supradiaphragmatic region through the esophagus's transition point in the diaphragm. It appears more frequently age-dependent as a result of abrasions due to phrenoesophageal membrane degeneration. ${ }^{1}$

\section{Case Report}

The 73-years-old patient, who was followed up in the palliative inpatient clinic with the diagnosis of inoperable endometrial cancer, was evaluated with low blood pressure despite fluid replacement and inotropic therapy. In the physical examination, the patient had a blood pressure of $80 / 50$ $\mathrm{mmHg}$, pulse 90 beats/min, respiratory rate 15/ min, fever $97.3 \mathrm{~F}$. Chest auscultation was compatible with decreased sounds in lung bases, heart sounds were normal, there were no pathological or additional sounds. Peripheral edema was not observed in the patient, and there was a small amount of hemorrhagic vaginal discharge that was observed intermittently. In the differential diagnosis, C-reactive protein level was $18 \mathrm{mg} / \mathrm{L}$,

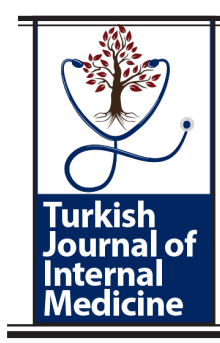

Received:February 03,2021;Accepted:March 3,2021;Published Online:March 6, 2021

Address for Correspondence:

Ali EROL

Health Sciences University, Yüksek İhtisas Training and Research Hospital, Internal Medicine 


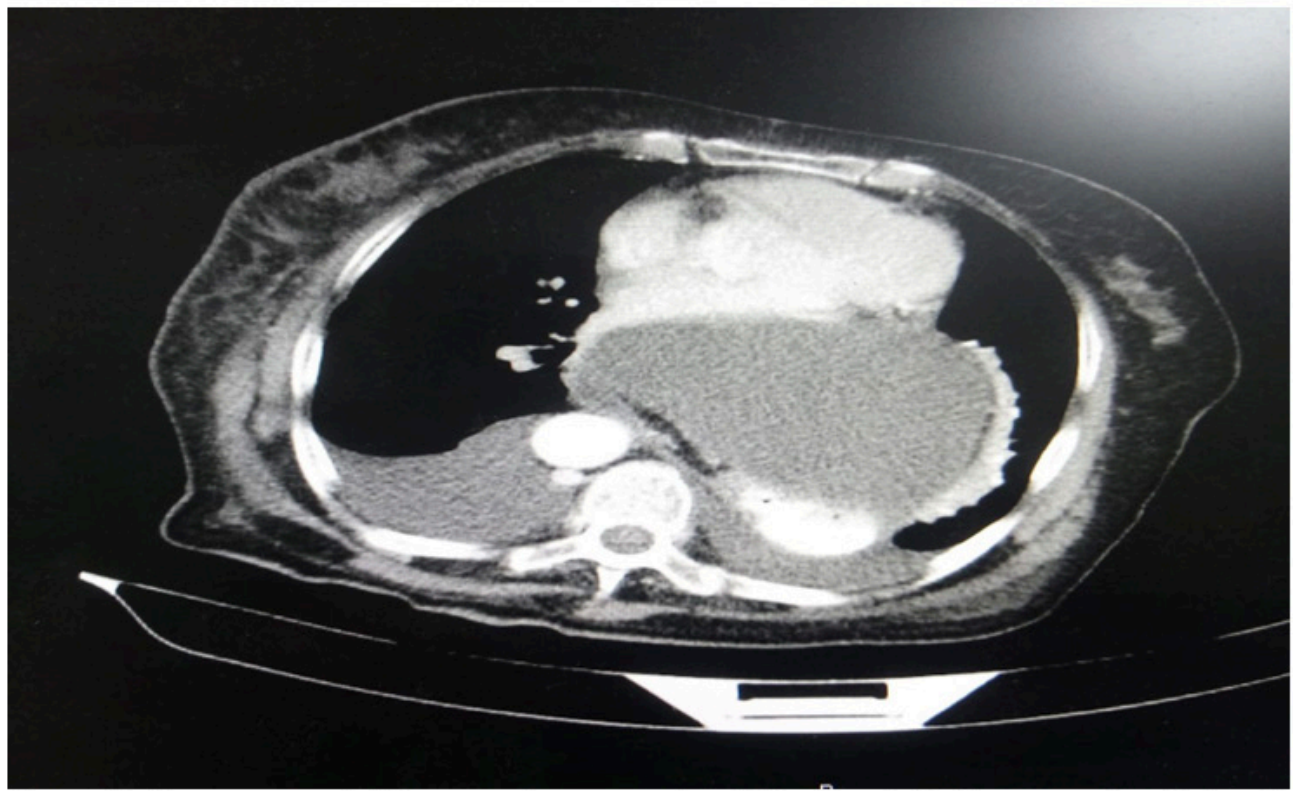

Figure 1. Thorax computed tomography represents a hiatus hernia that compressing the heart.

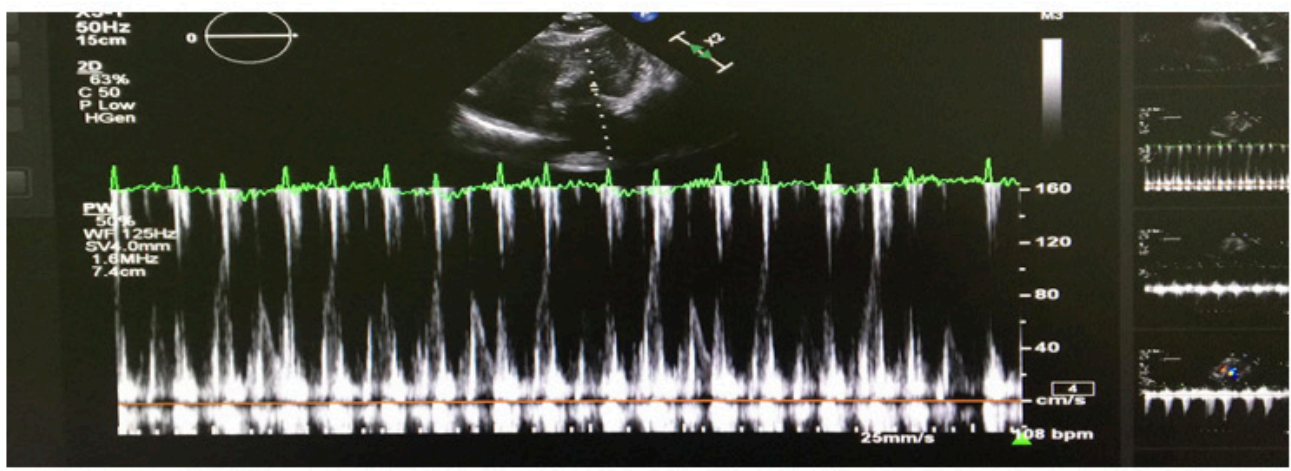

Figure 2. In the left ventricle inflow pulse wave doppler evaluation, a respiratory switch within physiological ranges was observed. Significant construction finding was not detected.

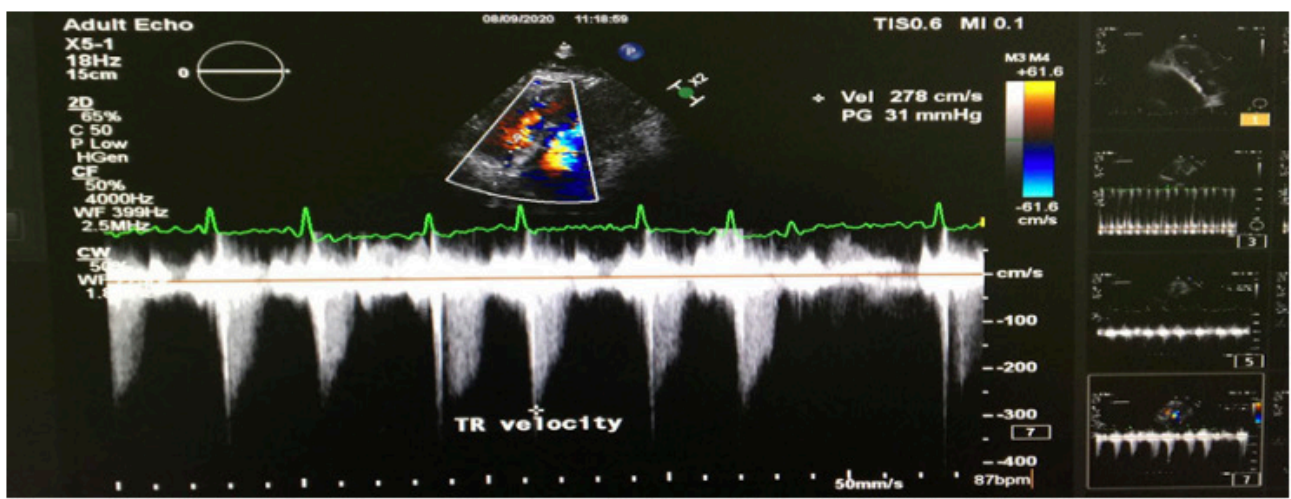

Figure 3. In the continued wave doppler evaluation obtained from the tricuspid regurgitation jet flow, the tricuspid regurgitation peak jet velocity was detected as $2.8 \mathrm{~m} / \mathrm{sec}$.

hemoglobin level was $12.4 \mathrm{~g} / \mathrm{dL}$, and no decrease was observed during the follow-up. In the examinations requested for adrenal insufficiency, cortisol, blood glucose, sodium, potassium levels were $34 \mathrm{mg} / \mathrm{dL}, 79 \mathrm{mg} / \mathrm{dL}, 141 \mathrm{mmol} / \mathrm{L}$, and 3.5 $\mathrm{mEq} / \mathrm{L}$, respectively. Thyroid functions were within normal limits (fT3: $1.3 \mathrm{pg} / \mathrm{mL}$ and fT4: 0.7 $\mathrm{ng} / \mathrm{dL})$. A mass compressing the heart was obser- ved with a transthoracic echocardiogram. A hiatus hernia compressing the heart was observed in thorax computed tomography (Figure 1). Nasogastric decompression was recommended for a general surgery consultation. After nasogastric decompression, the patient's inotropic therapy requirement was decreased and discontinued during the follow-up. The echocardiographic review 
showed regressed compression findings, and intracardiac filling pressures were within normal limits (Figure 2 and 3 ). The patient's clinical findings improved, and improvement was confirmed by echocardiographic examination, and vital measurements reached normal values. Our patient, whose general well-being continued in the following days, was discharged with recommendations.

\section{Discussion}

The patient, who had treatment-resistant hypotension, was shown objectively by the hiatus hernia's compression by tomography scan and transthoracic echocardiographic evaluation and was successfully treated with nasogastric decompression. The definitive diagnosis of hiatal hernia, whose incidence increases with age, can be diagnosed with barium imaging as well as computed tomography. Although treatment is surgical, conservative approaches such as eating less, not sleeping on a full stomach, sleeping with a few pillows are also included. Even though they are generally asymptomatic, larger ones may present with different clinics. ${ }^{2}$ Adrenal insufficiency was not considered in the differential diagnosis of treatment-resistant hypotension in our patient since concurrent hyperkalemia, hyponatremia, hypoglycemia was not present, and cortisol levels were within normal limits. Thyroid function tests were within normal limits. Despite a mild C-reactive protein elevation (18 $\mathrm{mg} / \mathrm{dL})$, sepsis was not considered because there were no accompanying findings such as leukocytosis/ leukopenia, hyperthermia/hypothermia, and hypoxemia. In the follow-up of the patient, there was no hemoglobin decrease or any bleeding findings. No symptoms such as nausea, vomiting, diarrhea, or using antihypertensive or diuretics therapy suggest hypovolemia. There was no dyspnea or urticarial rash suggestive of anaphylaxis. In another case report ${ }^{3}$, dyspnea at exertion was reported, but our patient had no effort dyspnea. Though in a published case ${ }^{4}$, arrhythmia and acute heart failure was reported during the follow-up, our patient also did not represent any finding considering arrhythmia, but she had pyrosis and early satiety symptoms. In another case $^{5}$, ST-T changes were reported in ECG, which is not valid for our patient. Considering these rarely reported clinical findings in the literature, it is important to reveal the etiological factors to initiate effective treatment earlier.

\section{Conflict of Interests}

Authors declare that there are none.

\section{Acknowledgment}

This study has been presented in $17^{\text {th }}$ Uludag Internal Medicine National Winter Congress, $6^{\text {th }}$ Bursa Family Medicine Association National Congress, $11^{\text {th }}$ Uludag Internal Medicine Nursing Congress, 5-7 March 2021, Bursa, Turkey.

\section{References}

1. Paterson WG, Kolyn DM. Esophageal shortening induced by short-term intraluminal acid perfusion in opossum: a cause for hiatus hernia? Gastroenterology. 1994 Dec;107(6):1736-40. doi: 10.1016/00165085(94)90814-1.

2. Goyal RK. Diseases of the esophagus. In: Harrison TR, Isselbacher KJ, Wilson JD, eds. Harrison's Principles of Internal Medicine. 13th ed. New York: McGrawHill; 1994:1355-63.

3. Ito H, Kitami M, Ohgi S, Ohe H, Ozoe A, Sasaki H, Konnai T. Large hiatus hernia compressing the heart and impairing the respiratory function: a case report. J Cardiol. 2003 Jan;41(1):29-34 (in Japanese).

4. Siu CW, Jim MH, Ho HH, Chu F, Chan HW, Lau CP, Tse HF. Recurrent acute heart failure caused by sliding hiatus hernia. Postgrad Med J. 2005 Apr;81(954):268-9. doi: 10.1136/pgmj.2004.023416.

5. Morris JC, Shelburne PF, Orgain ES. Coronary disease and hiatal hernia: An example in support of the existence of a viscerocardiacreflex. JAMA. 1963 Mar2;183(9):78890. doi: 10.1001/jama.1963.63700090030020. 